\title{
Phytotoxicity of Discula destructiva Culture Filtrates to Cornus spp. and the Relationship to Disease Symptomology
}

\author{
D. E. Wedge, Department of Forest Resources, Clemson University, Clemson, SC 29734-1003; M. B. Riley, De- \\ partment of Plant Pathology and Physiology, Clemson University, Clemson, SC 29634-0377; and F. H. Tainter, \\ Department of Forest Resources, Clemson University, Clemson, SC 29634-1003
}

\begin{abstract}
Wedge, D. E., Riley, M. B., and Tainter, F. H. 1999. Phytotoxicity of Discula destructiva culture filtrates to Cornus spp. and the relationship to disease symptomology. Plant Dis. 83:377-380.

Discula destructiva culture filtrates and partially purified culture filtrates (PPCF) inhibited radish (Raphanus sativus) and dogwood (Cornus) species in a seedling root bioassay. Noninoculated potato-dextrose broth (PDB) extracted and separated in a similar manner also inhibited seedling growth. Reverse phase high performance liquid chromatography separated this inhibitory activity into two fractions, with one associated with the inhibitory action observed with PDB controls. The active fraction without interference with PDB, determined by bioassays, was extracted from cultures grown on Murishige-Skoog (MS) medium, which had no inhibitory activity associated with noninoculated controls. The active fraction was tested in a leaf overlay technique using 10 Cornus spp. All dogwood species were sensitive to the fraction and exhibited necrotic lesions bounded by a red margin, typical of dogwood anthracnose. The active fraction was translocated in Cornus alba to the leaf margin. C. canadensis showed minimal primary lesion formation but developed leaf curling and necrosis on leaf margins of newly emerging leaves, indicating apical translocation of the fraction from the application site. Comparison of three D. destructiva (Type 1) isolates and a Discula sp. (Type 2) isolate for production of the active fraction showed that the Type 2 isolate did not produce detectable amounts of the active component.
\end{abstract}

Additional keyword: toxins

Since dogwood anthracnose was identified in the Northeastern United States (3) and its causal agent, Discula destructiva, was described (12), it has caused a serious decline in flowering dogwoods (Cornus florida) in the Appalachian mountains of the United States $(13,22,23)$. The severity and impact of this disease has been well documented $(4,5)$. In studies of dogwood anthracnose, two types of fungal isolates were isolated from diseased leaves and twigs. These isolates were distinguished by their ability to utilize gallic acid (17) and by DNA amplification fingerprinting $(1,16)$ and were designated Type 1 and Type 2 (21). Type 1 is $D$. destructiva, the described pathogen. The relevance of the Type 2 isolates is not known.

Corresponding author: D. E. Wedge

E-mail: dwedge@olemiss.edu

Current address for D. E. Wedge: PO Box 8048; USDA, ARS, NPURU; National Center for the Development of Natural Products; University of Mississippi, University 38677.

Technical Contribution No. 4431 of the South Carolina Agriculture and Forestry Research System.

Accepted for publication 4 January 1999.

Publication no. D-1999-0209-01R

(C) 1999 The American Phytopathological Society
Elucidation of the pathogenic mechanism of $D$. destructiva in the progression of disease symptoms would contribute significantly to our knowledge of the physiology of this disease. Necrosis of cells preceding hyphal proliferation (19) and identification of four phytotoxic phenols from culture filtrates (18) suggest an association between toxin production and symptom development in dogwood anthracnose. Venkatasubbaiah and Chilton (18) previously isolated phytotoxic phenols from a Discula sp. isolated from diseased dogwood tissue. The involvement of these phytotoxins in symptom development has not been investigated and no comparisons have been made between isolates of $D$. destructiva and the unidentified Type 2 Discula species.

The objectives of our research were to (i) extract fungal toxins from culture filtrates of Discula spp. (D. destructiva, Type 1, and Discula sp., Type 2), (ii) demonstrate the involvement of fungal toxin production in symptom expression, and (iii) determine the sensitivity of various Cornus spp. to toxins.

\section{MATERIALS AND METHODS}

Fungal isolates and biomass production. Four Discula isolates were obtained from cooperators; Type-1 isolates (D. destructiva) from S. D. McElreath, Department of Forest Resources, Clemson Uni- versity (isolate 100); M. L. Daughtrey, Long Island Horticultural Research Laboratory, Cornell University (isolates 123 and 125); and a Type-2 isolate (Discula sp.) from R. L. Anderson, USDA Forest Service, Asheville, NC (isolate 99). Two of these isolates were used in previously published DNA amplification fingerprinting studies of D. destructiva and Discula sp. Type 2 isolates $(1,16)$. Isolates 99 and 123 were identified as NC-2 and NY-329, respectively, in these studies. Cultures were initiated from mycelial plugs, grown on potato-dextrose agar (PDA) for 21 days at $23 \pm 2{ }^{\circ} \mathrm{C}$, and transferred to oak sporulation medium (9) for conidial production. Potato-dextrose broth (PDB, $100 \mathrm{ml}$ ) was inoculated with $1.0 \times 10^{6}$ conidial suspensions prepared in sterile distilled water for all four isolates. Murashige-Skoog (MS) medium (10) containing $30 \mathrm{~g} / \mathrm{liter}$ of sucrose was inoculated with isolate 100 . Stationary cultures were maintained at 23 $\pm 2{ }^{\circ} \mathrm{C}$ under ambient laboratory lighting (3 $\pm 1 \mu \mathrm{mol}$ ) with cool white fluorescent lights and 12-h photoperiods. PDB cultures were grown for 3 months and MS cultures were grown for 10 months.

Extract preparation. Extraction and separation procedures were a modification of procedures used to study toxins associated with Pythium spp. (6). Cultures were initially filtered through Whatman \#2 and \#42 filter papers and a GF/F $0.7-\mu$ glass microfibril filter to remove hyphae. Culture filtrates were run through YM100 (>100,000 Da) and YM3 (>3,000 Da) ultrafiltration membranes (Amicon Inc., Beverly, MA). The final low-molecularweight filtrate was stored overnight $\left(-80^{\circ} \mathrm{C}\right)$ and then lyophilized. Lyophilate was reconstituted with $50 \%$ methanol: water $(\mathrm{vol} / \mathrm{vol})$, stored overnight at $5^{\circ} \mathrm{C}$, filtered to remove precipitates, and rotary evaporated $\left(60^{\circ} \mathrm{C}\right)$ under 600 to $700 \mathrm{~mm}$ $\mathrm{Hg}$ vacuum to dryness. Residue was reconstituted with $80 \%$ methanol:water (vol/ vol) and final volume was adjusted to $2 \%$ $(\mathrm{vol} / \mathrm{vol})$ of the original culture filtrate. This partially purified culture filtrate (PPCF) resulted in a 50-fold concentration of toxic metabolites. Samples were obtained at each stage of the purification procedure and evaluated for activity using the radish seedling root bioassay $(7,11)$.

High performance liquid chromatography (HPLC) was used to further separate the PPCF using a Hewlett-Packard 1090 
HPLC (Hewlett-Packard Inc. Avondale, PA) equipped with a diode array detector set at 206, 240, and $254 \mathrm{~nm}$, and reverse phase $\mathrm{C}_{18}$ column (Rexchrom, $3 \mu, 10 \mathrm{~cm} \times$ $4.6 \mathrm{~mm}$ i.d.; Regis Chemical Co., Morton Grove, IL). The solvent was 2:98 acetonitrile:water for $10 \mathrm{~min}$, then increased to 15:85 acetonitrile:water over the next 10 min, followed by $100 \%$ acetonitrile for 10 min. Flow rates were $0.4 \mathrm{ml} / \mathrm{min}$ for $10 \mathrm{~min}$ and then $0.5 \mathrm{ml} / \mathrm{min}$ for $20 \mathrm{~min}$ with $250 \mu \mathrm{l}$ of sample injected. HPLC fractions were different analysis runs. Fractions were dried at $50^{\circ} \mathrm{C}$, resuspended in HPLC grade water, and subjected to bioassay tests.

In vitro toxin bioassay. Toxicity of Discula spp. culture filtrates was tested using modifications of seedling root growth bioassays which have been used extensively as indicators of allelopathic and phytotoxic compounds $(7,11,14,20)$. Cornus spp. have very complex dormancy requirements and are not good candidates for seedling bioassays; therefore, seeds from three Cornus spp. were compared with radish (Raphanus sativus) seeds in a seedling bioassay to determine if a radish seedling bioassay could replace Cornus spp. seedlings in initial testing. Seedling 90-mm Petri plates containing a piece of Whatman \#2 filter paper to which $8 \mathrm{ml}$ of culture filtrate or equivalent control solution (diluted 1:10 with sterile, distilleddeionized water) were added. A total of 10 Cornus spp. or radish seeds were added to each plate. Stones from Cornus spp. were harvested from stratification medium when cracked naturally by the enlarging embryos. Fleshy embryos were removed by hand and disinfested with $0.525 \%$ sodium hypochlorite for $10 \mathrm{~min}$, followed by three sterile, distilled-water rinses. Petri dishes were placed on a countertop under room lighting with cool white fluorescent lights and a 12 -h photoperiod at $22 \pm 2{ }^{\circ} \mathrm{C}$. Root growth was measured 4 days after treatment (DAT) for radish and 7 DAT for Corcollected at 5-, 1-, and 0.5-min intervals in root bioassays were conducted in sterilized

nus spp. A completely randomized design was used for the seedling root bioassay using three Petri plate replicates for each treatment, with each replicate containing 10 seeds.

In vivo bioassay. A modification of the leaf-puncture bioassay $(8,15)$ was used to study the effects of extracts on Cornus spp. leaves. Samples obtained from two chromatographic runs of the isolate $100 \mathrm{MS}$ culture filtrate at 23.5 to $24.5 \mathrm{~min}$ were used to inoculate Cornus spp. MS broth without fungal inoculum and subjected to the same lyophilization, evaporation, reconstitution, and HPLC collection procedures was used as the control. Serial dilutions $(1: 2,1: 4$, and 1:8) of the samples were tested in a dose-response format. Each leaf in the second leaf pair was wounded twice approximately $1 \mathrm{~cm}$ apart with a 26-gauge tuberculin needle. The two wound sites on each leaf divided the leaf into approximately three equal portions. Each puncture site was then overlaid with $10 \mu \mathrm{l}$ of serial-diluted HPLC culture filtrate samples or sterile water. Control plants were inoculated in the same manner using the HPLC-prepared MS control (serial dilutions of 1:2,1:4, and 1:8) and sterile water.

A total of 10 Cornus spp. were grown in GA7 magenta jars (Sigma Chemical Co., St. Louis) containing $80 \mathrm{~cm}^{3}$ of sand and $25 \mathrm{ml}$ of Hoagland's \#2 basal salt mixture (Sigma Chemical Co.). Seedlings (6 to 8 $\mathrm{cm}$ in height; average seedling age, 2 to 3 months) were used to test the response of Cornus spp. to HPLC samples of PPCF. Experiments were repeated twice with three replicates of each species used for the PPCF treatments and one replicate for the control treatment.

Analysis of variance (ANOVA) and the post hoc Tukey's honestly significant difference (Tukey's HSD) were used for analysis, and post hoc procedures were used to test significance of treatment effects. Duncan's multiple-range test was used for comparison of necrotic lesion size

Table 1. Comparison of mean root growth of radish (Raphanus sativus), Cornus racemosa, and $C$. amomum seedlings exposed to culture filtrates of Discula destructiva (Isolates 100, 123, and 125) and Discula sp. (Isolate 99) grown on potato-dextrose broth (PDB) and Murashige-Skoog (MS) media following filtration to remove hyphae ${ }^{y}$

\begin{tabular}{lcccc}
\hline & \multicolumn{4}{c}{ Root length by species $(\mathbf{m m})^{\mathbf{z}}$} \\
\cline { 2 - 5 } Filtrate & R. sativus & C. racemos & C. amomum & C. florida \\
\hline Water control & $41.8 \mathrm{a}$ & $20.6 \mathrm{a}$ & $14.5 \mathrm{a}$ & $16.8 \mathrm{a}$ \\
MS control & $30.1 \mathrm{~b}$ & $12.0 \mathrm{bc}$ & $12.7 \mathrm{a}$ & $8.8 \mathrm{ab}$ \\
PDB control & $14.4 \mathrm{c}$ & $3.5 \mathrm{~d}$ & $2.4 \mathrm{~b}$ & $12.7 \mathrm{a}$ \\
Isolate 100-PDB & $8.4 \mathrm{c}$ & $2.7 \mathrm{~d}$ & $2.4 \mathrm{~b}$ & $2.9 \mathrm{~b}$ \\
Isolate 100-MS & $7.9 \mathrm{c}$ & $2.4 \mathrm{~d}$ & $1.9 \mathrm{~b}$ & $2.0 \mathrm{~b}$ \\
Isolate 123-PDB & $10.9 \mathrm{c}$ & $4.7 \mathrm{~cd}$ & $2.2 \mathrm{~b}$ & $2.7 \mathrm{~b}$ \\
Isolate 125-PDB & $11.9 \mathrm{c}$ & $4.1 \mathrm{~cd}$ & $2.6 \mathrm{~b}$ & $2.5 \mathrm{~b}$ \\
Isolate 99-PDB & $33.3 \mathrm{ab}$ & $15.8 \mathrm{ab}$ & $11.7 \mathrm{a}$ & $12.8 \mathrm{a}$ \\
\hline
\end{tabular}

${ }^{y}$ Mean root length for seedlings is listed for plant species by fungal isolate. Treatment in each experiment consists of three replicate plates with 10 seeds per plate. Results are averages of two experiments.

${ }^{\mathrm{z}}$ Means within species followed by the same letter are not significantly different using Tukey's honestly significant difference $(P<0.05)$. in different Cornus spp. Pearson's correlation coefficient $(r)$ was used to evaluate the strength of the relationship between species. An overall experiment-wide level of a type 1 error was set at 0.5 . Statistical analysis was performed using PC-SAS (release 6.04; SAS Institute Inc., Cary, NC).

\section{RESULTS}

Results from C. racemosa, C. amomum, $C$. florida, and $R$. sativus seedling bioassays using culture filtrates of Type $1 D$. destructiva (isolates 100, 123, and 125), Type 2 Discula sp. (isolate 99), and controls showed a high correlation between the results of Cornus spp. and radish root growth bioassays (Table 1). Pearson correlation coefficients $(r)$ by species, replicate, and individual seedlings were significant $(P<0.01)$ where $r$ for root length by species was $R$. sativus with $C$. racemosa $(r$ $=0.987), C$. amomum $(r=0.894)$, and $C$. florida $(r=0.852)$, respectively. Comparisons of root lengths showed that $C$. florida correlated more closely with radish than with the other dogwood species. The Pearson correlation coefficient for root length by species for $C$. florida was lower with $C$. racemosa $(r=0.803)$ and $C$. amomum $(r=$ $0.758)$ with a lower level of significance $(P$ $<0.05)$. These data demonstrate that the radish seedling bioassay could be used for detection of phytotoxic compounds in culture filtrates of $D$. destructiva. There was significant inhibition in noninoculated PDB controls when compared to water and MS controls. The inhibition was reduced in cultures inoculated with Type 2 Discula isolate 99 .

Evaluation of Discula isolates. Type 1 D. destructiva (isolates 100, 123, and 125) were not significantly different from each other but were significantly different from Type 2 Discula sp. (isolate 99; Table 1), indicating a significant difference in the toxicity of the Type 2 isolate and the Type 1 D. destructiva. Filtrates from isolate 100 grown in MS inhibited root growth significantly when compared to the MS control for both radish and Cornus spp.

The PPCF original culture filtrate, membrane retentates, water, and PDB controls were compared utilizing the radish seedling bioassay. Isolate 100 results (Table 2) show a significant growth inhibition of the PPCF when compared with all other separation fractions and controls. The original culture filtrate inhibited root growth significantly compared to the PPCF, indicating some loss of activity during the molecular sieving. These comparisons indicated that the PPCF contained low-molecular-weight compounds $(<3,000$ $\mathrm{Da})$ that were inhibitory to root growth. Stimulation of root growth was observed in root growth with the retentate from the 3,000-Da ultrafiltration membrane.

Significant inhibitory activity was detected in two fractions, 0 to 5 and 20 to 25 
min, isolated from HPLC analysis runs of Discula culture filtrates grown in MS or PDB medium (Table 3). The PDB control had inhibitory activity associated with the 0 - to 5-min fraction. No inhibition was observed in any fraction from the MS control and this fraction of the culture filtrate was eliminated from the further study.

The 20- to 25-min fraction was further separated into five 1-min intervals for use in the root growth bioassay for the comparison of the different isolates (Table 4). Significant differences in activity were demonstrated between Type 1 (D. destructiva, isolates 100, 123, and 125) and the Type 2 Discula isolate (isolate 99) in the 23 - to 25 -min fraction $(P<0.001)$. No differences were observed between the three Type 1 isolates (100, 123, and 125). The 23- to 25-min interval was further separated into four 30-s intervals. Mean root inhibition was greatest for roots exposed to the 23.5 - to 24.5 -min fractions ( $P$ $<0.001)$. No differences in growth inhibition among Type 1 isolates $(100,123$, and 125) were detected.

In vivo assay. The HPLC 23.5 - to 24.5 min fraction, from isolate 100 grown in MS broth, was tested on 10 Cornus spp. (C. florida, C. controversa, C. alba, C. nuttallii, C. kousa, C. kousa var. chinensis, C. canadensis, C. amomum, C. racemosa, and $C$. angustata) using a leaf overlay technique. Relative necrotic lesion size formed following application of the active fraction was measured 1, 3, and 7 DAT of leaves. All species developed necrotic lesions in a dose-related response, while no necrosis or wound response was noted in control plants inoculated with the MS control fraction. Typical symptoms of $D$. destructiva on $C$. florida in natural habitats include blighting of young leaves and formation of necrotic lesions forming shot holes bordered with a raised, red-purple margin. Based on the necrotic lesions 1 DAT, the various species were placed in three major groups (Table 5). The most

Table 2. Comparison of mean root growth in radish seedlings following separation and molecular sieving of culture filtrates of Discula destructiva (Isolate 100) grown on potato-dextrose broth $(\mathrm{PDB})^{\mathrm{y}}$

\begin{tabular}{lc}
\hline Fraction & Mean $\pm \mathbf{S E}^{\mathbf{z}}$ \\
\hline PDB control & $25.22 \pm 1.16 \mathrm{bc}$ \\
Water control & $23.93 \pm 1.85 \mathrm{bc}$ \\
$\begin{array}{l}\text { Retentate from } \\
\text { YM100 membrane }\end{array}$ & $29.43 \pm 1.53 \mathrm{~b}$ \\
Retentate from & $35.28 \pm 1.86 \mathrm{a}$ \\
$\quad$ YM3 membrane & $14.55 \pm 1.42 \mathrm{~d}$ \\
Partially purified & culture filtrate \\
Original culture filtrate & $8.51 \pm 0.43 \mathrm{e}$ \\
\hline
\end{tabular}

${ }^{\mathrm{y}}$ Mean root lengths are of three replicate plates with 10 seeds per plate.

${ }^{\mathrm{z}}$ Root length (mm); SE = standard error. Treatment means followed by the same letter are not significantly different using Tukey's honestly significant difference $(P<0.05)$. sensitive group included $C$. nuttallii and $C$. controversa, and intermediate sensitivity included $C$. racemosa and $C$. alba. Six Cornus spp. demonstrated less sensitivity to the fraction, including $C$. kousa, $C$. amomum, C. florida, C. canadensis, $C$. kousa var. chinensis, and C. angustata.

Translocation of fungal metabolites within leaves was observed in $C$. alba 3 DAT, when secondary lesions were noted along the leaf margin, indicating distal transport of the toxic fraction. These lesions coalesced with the primary lesion by 7 DAT. A red margin developed along the edge of the lesion. This symptom is commonly seen in lesions on naturally infected dogwood. Leaf curling and necrosis along the leaf margin occurred in newly emerging leaves above the secondary leaf pair used for the leaf overlay assay in $C$. $c a$ nadensis, indicating apical transport of the active fraction from the application site.

\section{DISCUSSION}

Seedling bioassays using radish and various dogwood species were useful for in vitro and in vivo detection of toxic fungal metabolites associated with $D$. destructiva. The relative elapsed time for the radish bioassays and their sensitivity was consistent with previous reports (24). Results from the leaf puncture assay were much more variable due to the variability of plants and the confines of the growth system which resulted in less sensitivity in determining differences when compared to the radish or Cornus spp. seedling bioassays. The radish bioassay proved to be a sensitive and simple test for the initial detection of toxic metabolites produced by $D$. destructiva without the problems associated with stratification and breaking of dormancy requirements of Cornus spp. seeds.

HPLC was efficient for the separation and partial purification of $D$. destructiva phytotoxins. There are probably several compounds in this fraction, and further research is necessary to separate and identify the specific toxic compound or compounds and compare them with those previously identified in Discula sp. which was most likely $D$. destructiva (18). The inhibition associated with the PDB control emphasizes the importance of controls and suggests that PDB may not be the most suitable medium for toxicological studies of plant pathogens. The use of a chemically defined medium would be a much more suitable growth medium for toxicological studies. The HPLC fraction, 0 to 5 min, needs to be further isolated and its involvement in symptom development studied.

The dogwood leaf overlay with the active fraction purified using HPLC indicated that $D$. destructiva produces one or more phytotoxins in culture filtrates that can produce in vivo symptoms similar to those observed in the field, demonstrating the involvement of a phytotoxin or phyto-

Table 4. Comparison of mean root growth of radish seedlings exposed to 1-min fractions of the 23-25 min interval collected from HPLC runs for three Discula destructiva Type 1 isolates $(100,123$, and 125) and Discula sp. Type 2 isolate (99) culture filtrates grown on potatodextrose broth (PDB) or Murishige-Skoog (MS) media ${ }^{y}$

\begin{tabular}{lrr}
\hline & \multicolumn{2}{c}{ 1-Min HPLC intervals $^{\mathbf{z}}$} \\
\cline { 2 - 3 } Isolate & \multicolumn{1}{c}{$\mathbf{2 3}$ to $\mathbf{2 4}$} & \multicolumn{1}{c}{ 24 to $\mathbf{2 5}$} \\
\hline 100-PDB & $9.5 \pm 0.6 \mathrm{a}$ & $8.5 \pm 0.5 \mathrm{a}$ \\
123-PDB & $11.6 \pm 0.7 \mathrm{a}$ & $12.2 \pm 0.7 \mathrm{a}$ \\
125-PDB & $10.1 \pm 0.6 \mathrm{a}$ & $13.5 \pm 0.8 \mathrm{a}$ \\
99-PDB & $46.9 \pm 2.3 \mathrm{~b}$ & $42.9 \pm 2.2 \mathrm{~b}$ \\
100-MS & $14.1 \pm 0.8 \mathrm{a}$ & $13.7 \pm 0.8 \mathrm{a}$ \\
\hline
\end{tabular}

y Means are the average of two experiments, each with three replicate plates per fraction with 10 seeds per plate.

${ }^{\mathrm{z}}$ Mean \pm standard error. HPLC retention time fractions with significant growth inhibition $(P$ $<0.001)$. Means within a time interval followed by the same letter are not significantly different using Tukey's honestly significant difference $(P<0.05)$

Table 3. Comparison of mean root growth of radish seedlings exposed to 5-min fractions collected from high performance liquid chromatography (HPLC) runs separating Discula destructiva Isolate 100 potato-dextrose broth (PDB) and Murashige-Skoog (MS) culture filtrates and the corresponding controls ${ }^{\mathrm{x}}$

\begin{tabular}{lrccc}
\hline Time $(\mathbf{m i n})^{\mathbf{y}}$ & 100-PDB $^{\mathbf{z}}$ & PDB Control & 100-MS & MS Control \\
\hline $0-5^{*}$ & $5.0 \pm 0.5 \mathrm{a}$ & $6.25 \pm 1.0 \mathrm{c}$ & $20.4 \pm 1.1 \mathrm{ac}$ & $34.2 \pm 1.4 \mathrm{a}$ \\
$5-10$ & $35.2 \pm 1.9 \mathrm{~b}$ & $49.8 \pm 2.8 \mathrm{a}$ & $35.8 \pm 1.7 \mathrm{bc}$ & $38.0 \pm 2.0 \mathrm{a}$ \\
$10-15$ & $39.0 \pm 2.2 \mathrm{~b}$ & $42.5 \pm 2.8 \mathrm{ab}$ & $43.8 \pm 2.0 \mathrm{~b}$ & $39.8 \pm 2.4 \mathrm{a}$ \\
$15-20$ & $34.4 \pm 2.4 \mathrm{~b}$ & $36.7 \pm 1.8 \mathrm{~b}$ & $41.9 \pm 2.4 \mathrm{~b}$ & $41.2 \pm 1.9 \mathrm{a}$ \\
$20-25^{*}$ & $8.1 \pm 0.5 \mathrm{a}$ & $35.3 \pm 1.6 \mathrm{~b}$ & $11.3 \pm 0.7 \mathrm{a}$ & $38.8 \pm 1.7 \mathrm{a}$ \\
$25-30$ & $34.9 \pm 1.9 \mathrm{~b}$ & $42.2 \pm 2.4 \mathrm{ab}$ & $38.7 \pm 1.6 \mathrm{bc}$ & $40.8 \pm 2.0 \mathrm{a}$ \\
$30-35$ & $39.0 \pm 2.1 \mathrm{~b}$ & $44.8 \pm 2.5 \mathrm{a}$ & $55.4 \pm 9.4 \mathrm{~b}$ & $43.1 \pm 2.0 \mathrm{a}$ \\
\hline
\end{tabular}

${ }^{x}$ Means are the average of two experiments each with three replicate plates per fraction with 10 seeds per plate.

y HPLC retention time fractions. Fractions demonstrating significant growth inhibition are indicated with an asterisk $(P<0.001)$. Contrasted means for $100-P D B$ versus PDB control and $100-$ MS versus MS control were significantly different for the 20- to 25-min intervals using Tukey's honestly significant difference (HSD; $P<0.05$ ).

${ }^{z}$ Means \pm standard error. Means within columns for various culture filtrates followed by the same letter are not significantly different using Tukey's HSD $(\mathrm{p}<0.05)$. 
Table 5. Comparison of necrotic lesion size $\left(\mathrm{mm}^{2}\right)$ and sensitivity of various Cornus spp. in planta 1 day after application of partially purified culture filtrate (PPCF) separated on high performance liquid chromatography ${ }^{\mathrm{x}}$

\begin{tabular}{lcc}
\hline Cornus spp. & Lesion size $^{\mathbf{y}}$ & Sensitivity to PPCF \\
\hline C. nuttalliz $^{\mathrm{z}}$ & $46.0 \pm 19.1 \mathrm{a}$ & High \\
C. controversa & $31.8 \pm 3.7 \mathrm{~b}$ & High \\
C. racemosa & $19.2 \pm 4.2 \mathrm{bc}$ & Intermediate \\
C. alba & $17.7 \pm 7.2 \mathrm{bc}$ & Intermediate \\
C. kousa & $14.7 \pm 2.6 \mathrm{c}$ & Low \\
C. amomum & $12.7 \pm 3.5 \mathrm{c}$ & Low \\
C. florida & $12.0 \pm 5.1 \mathrm{c}$ & Low \\
C. canadensis & $11.2 \pm 2.0 \mathrm{c}$ & Low \\
C. kousa var. chinensis & $8.5 \pm 3.6 \mathrm{c}$ & Low \\
C. angustata & $7.8 \pm 2.0 \mathrm{c}$ & Low \\
\hline
\end{tabular}

$\mathrm{x}$ Mean lesion diameters are the average of six plants from two experiments.

y Necrotic lesion size $\left(\mathrm{mm}^{2}\right) \pm$ standard error. Means followed by the same letter are not significantly different using Duncan's multiple range test.

${ }^{\mathrm{z}}$ From one experiment, $n=2$.

toxins in symptom expression of dogwood anthracnose. These findings support previous histological evidence in leaves with few visible hyphae, indicating the involvement of a toxic metabolite (19). Daley (2) stated that minimum proof for the role of a toxin in disease is the reproduction of that symptom by extracellular products of the pathogen. This has been demonstrated in this study with the results of the leaf overlay assay of purified culture filtrates.

Yoder (24) stated that pathological significance should be assessed by evaluations of the correlation between (i) toxin production and disease production by the pathogen and (ii) sensitivity to the toxin and susceptibility of the plant to disease. Bioassay data indicate that the three $D$. destructiva Type 1 isolates tested produced toxic metabolites. No production of toxic metabolites was detected in the Discula Type 2 isolate, lending further evidence that this isolate is not D. destructiva. The Type 2 Discula sp. isolate was consistently shown to be different, toxicologically, from D. destructiva. This supports the designation that $D$. destructiva (Type 1) is taxonomically different from the unidentified Discula sp., Type 2 (21). Further studies are needed to compare toxin production and disease development by various isolates. This has been hampered by problems associated with the inoculation of Cornus spp. with $D$. destructiva to produce disease.

In Cornus spp. seedlings, the $D$. destructiva-active fraction caused rapid necrosis of leaf tissue (less than $24 \mathrm{~h}$ ), suggesting a possible attack on the plasma membrane. In older tissue, necrosis is prominent in 3 days and in younger tissue, the whole leaf can be blighted. Symptoms indicate that these compounds diffuse apoplasticly, causing an increase in leaf necrosis between 1 and 3 DAT. Xylem translocation of the active agent can cause secondary necrotic lesions to appear in sites distal to the wound site between 3 and 7 DAT. In $C$. canadensis, translocation of the active fraction from the second leaf pair upwards resulted in marginal necrosis in emerging leaves. It appears that a primary response of tissue necrosis results on contact, with subsequent translocation to sensitive meristematic areas along the leaf margin or upwards to younger emerging leaves. These symptoms are consistent with those seen in forested settings and may help to explain the loss of canopy in flowering dogwoods and sensitivity of young seedlings.

\section{LITERATURE CITED}

1. Caetano-Anolles, G., Trigiano, R. N., and Windham, M. T. 1996. Sequence signatures from DNA amplification fingerprints reveal fine population structure of the dogwood pathogen Discula destructiva. FEMS Microbiol. Lett. 145:377-383.

2. Daly, J. M. 1981. Mechanism of Action. Pages 331-394 in: Toxins in Plant Disease. R. D. Durbin, ed. Academic Press, New York.

3. Daughtrey, M. L., and Hibben, C. R. 1983. Lower branch dieback, a new disease of northeastern dogwoods. (Abstr.) Phytopathology 73:365.

4. Daughtrey, M. L., and Hibben, C. R. 1994. Dogwood anthracnose: A new disease threatens two native Cornus species. Annu. Rev. Phytopathol. 32:61-73.

5. Daughtrey, M. L., Hibben, C. R., Britton, K. O., Windham, M. T., and Redlin, S. C. 1996. Dogwood anthracnose: understanding a disease new to North America. Plant Dis. 80:349-358.

6. Desitles, H., and Belanger, R. R. 1991. An in vitro system for studying the effects of $P y$ thium ultimum metabolites on Pelargonium $\times$ hortorum. Phytopathology 81:202-206.

7. Duke, S. O. 1986. Naturally occurring chemical compounds as herbicides. Rev. Weed Sci. $2: 17-44$.

8. Karr, A. L., Jr., Karr, D. B., and Strobel, G. A. 1974. Isolation and partial characterization of four host-specific toxins of Helminthosporium maydis (race t). Plant Physiol. 53:250-257.
9. McElreath, S. D., and Tainter, F. H. 1993. A sporulation medium for Discula destructiva, the dogwood anthracnose fungus. Curr. Microbiol. 26:117-121.

10. Murashige, T., and Skoog, F. 1962. A revised medium for rapid growth and bioassays with tobacco tissue culture. Physiol. Plant 15:473497.

11. Patterson, D. T. 1986. Allelopathy. Pages 111134 in: Research Methods in Weed Science. 3rd. ed. N. D. Camper, ed. Southern Weed Sci. Soc. Champaign, IL.

12. Redlin, S. C. 1991. Discula destructiva sp. nov., cause of dogwood anthracnose. Mycologia 83:633-642.

13. Santamour, F. S., Jr., McArdle, A. J., and Strider, P. V. 1989. Susceptibility of flowering dogwood of various provenances to dogwood anthracnose. Plant Dis. 73:590-591.

14. Streibig, J. C., and Kudsk, P., eds. 1993. Herbicide Bioassays. CRC Press, Boca Raton, FL.

15. Sugawara, F., Strobel, G., Strange, R., Siedow, J., Van Duyne, G. D., and Clardy, J. 1987. Phytotoxins from the pathogenic fungi Drechslera maydis and Dreshslera sorghicola. Proc. Natl. Acad. Sci. USA 84:3081-3085.

16. Trigiano R. N., Caetano-Anolles, G, Bassam, B. J., and Windham, M T. 1995. DNA amplification fingerprinting provides evidence that Discula destructiva, the cause of dogwood anthracnose in North America, is an introduced pathogen. Mycologia 87:490-500.

17. Trigiano, R. N., Gerhaty, N. E., Windham, M. T., and Brown, D. A. 1991. A simple assay for separating fungi associated with dogwood anthracnose. Proc. South. Nurserymen's Assoc. Res. Conf. 36:209-211.

18. Venkatasubbaiah, P., and Chilton, W. S. 1991. Toxins produced by the dogwood anthracnose fungus Discula sp. J. Nat. Prod. 54:12931297.

19. Walkinshaw, C. H., and Anderson, R. L. 1991. Histology of Cornus florida L. leaves infected naturally and artificially by Discula sp. U. S. Dep. Agric. For. Serv. Southeast. For. Exp. Stn. Res. Note SE-360.

20. Wedge, D. E., McElreath, S. D., and Tainter, F. H. 1993. A bioassay for studying toxic metabolites of Discula destructiva. (Abstr.) Phytopathology 83:1393.

21. Windham, M. T., Erbaugh, E. K., Montgomery-Dee, M. E., and Trigano, R. N. 1994. Frequency of Discula destructiva Redlin and an undescribed Discula species from dogwood tissue. (Abstr.) Phytopathology 84:778.

22. Windham, M. T., Montgomery, M. E., and Langdon, K. 1992. Distribution of dogwood anthracnose in the Great Smoky Mountain National Park and effects of proximity of water to plots and plot aspect on disease severity. In: Results of the 1991 Impact Assessment and Pilot Test in the Southeastern United States. J. L. Knighten and R. L. Anderson, eds. U. S. Dep. Agric. For. Serv. South. Reg. Prot. Rep. R8-PR 23.

23. Windham, M. T., Montgomery-Dee, M. E., and Langdon, K. 1993. Factors affecting dogwood antracnose severity in Great Smoky Mountains National Park. Pages 28-31 in: Proc. Reg. Dogwood Workshop, 7th. M. T. Windham, ed. Chattanooga, TN.

24. Yoder, O. C. 1981. Assay. Pages 45-78 in: Toxins in Plant Disease. R. D. Durbin, ed. Academic Press, New York. 